\title{
Factors associated with hospital mortality in critically ill patients with exacerbation of COPD
}

This article was published in the following Dove Press journal:

International Journal of COPD

\author{
Hamish Brown $1, *$ \\ Stefan Dodic 1 ,* \\ Sheen Sern Goh ${ }^{2}$ \\ Cameron Green ${ }^{3}$ \\ Wei C Wang' \\ Sameer Kaul ${ }^{4}$ \\ Ravindranath Tiruvoipati ${ }^{1,3}$ \\ 'Faculty of Medicine, Nursing, \\ and Health Sciences, Monash \\ University, Melbourne, VIC, \\ Australia; 'Department of Medicine, \\ Frankston Hospital, Melbourne, \\ VIC, Australia; ${ }^{3}$ Department of \\ Intensive Care Medicine, Frankston \\ Hospital, Melbourne, VIC, Australia; \\ ${ }^{4}$ Department of Respiratory Medicine, \\ Frankston Hospital, Melbourne, VIC, \\ Australia \\ *These authors contributed equally \\ to this work
}

Introduction: COPD is a leading cause of morbidity and mortality worldwide. Patients with COPD often require admission to intensive care units (ICU) during an acute exacerbation. Objective: This study aimed to identify the factors independently associated with hospital mortality in patients requiring ICU admission for acute exacerbation of COPD.

Methods: Patients admitted to the ICU of Frankston Hospital between January 2005 and June 2016 with an admission diagnosis of COPD were retrospectively identified from ICU databases. Patients' comorbidities, arterial blood gas results, and in-patient interventions were retrieved from their medical records. Outcomes analyzed included hospital and ICU length of stay (LOS) and mortality.

Results: A total of 305 patients were included. Mean age was 67.4 years. A total of $77 \%$ of patients required non-invasive ventilation; and $38.7 \%$ required invasive mechanical ventilation (IMV) for a median of 127.2 hours ( $S D=179.5)$. Mean ICU LOS was 4.5 days ( $S D=5.96)$, and hospital LOS was 11.6 days ( $\mathrm{SD}=13)$. In-hospital mortality was $18.7 \%$. Multivariate analysis revealed that patient age (odds ratio $[\mathrm{OR}]=1.06$; 95\% CI: $1.031-1.096)$, ICU LOS (OR =1.26; 95\% CI: 1.017-1.571), Acute Physiology and Chronic Health Evaluation-II score (OR =1.07; 95\% CI: $1.012-1.123$ ), and requirement for IMV (OR $=4.09$; 95\% CI: $1.791-9.324)$ to be significantly associated with in-hospital mortality.

Conclusion: Patient age, requirement for IMV, and illness severity were associated with poor patient outcomes.

Keywords: COPD, intensive care, mechanical ventilation, mortality, outcome, critically ill

\section{Introduction}

COPD is a progressive condition characterized by abnormal inflammatory processes in the lungs, leading to irreversible airflow limitation. ${ }^{1}$ COPD is one of the common causes of death, ${ }^{2}$ with current literature reporting in-hospital mortality rates ranging from $11 \%$ to $48 \% .^{3-14}$ In addition to this significant rate of mortality, COPD has a high level of morbidity and patients often require admission to the intensive care unit (ICU) during acute exacerbations. ${ }^{6}$ Patients admitted to ICU with COPD often have multiple comorbidities ${ }^{15}$ and present with acute respiratory failure as a result of an infective exacerbation or at the end stage of their disease. ${ }^{5,14}$

The ability of clinical or laboratory features to reliably predict the outcomes of patients admitted to the ICU with COPD has been assessed by a number of previous studies. ${ }^{3-6,14,16,17}$ These studies have produced conflicting results. Significant independent predictors were shown to include increased age, lower body mass index, high partial pressures of carbon dioxide $\left(\mathrm{PaCO}_{2}\right)$ at admission, renal failure, and forced expiratory volume in 1 second $\left.\left(\mathrm{FEV}_{1}\right)\right)^{3-6,14,16,17}$ However, these predictors were not consistent across studies, and significant predictors in one study were often non-significant
Tiruvoipati

Department of Intensive Care Medicine, Frankston Hospital, 2 Hastings Road, Frankston, VIC 3199, Australia

Tel +6I 43 I27 9347

Email travindranath@hotmail.com
International Journal of COPD 2018:13 236I-2366

(c) (i) () 2018 Brown et al. This work is published and licensed by Dove Medical Press Limited. The full terms of this license are available at https://www.dovepress.com/terms.php cc. ${ }_{\mathrm{BY}} \mathrm{NC}_{\text {and }}$ incorporate the Creative Commons Attribution - Non Commercial (unported, v3.0) License (http://creativecommons.org/licenses/by-n/3.0/). By accessing the work you hereby accept the Terms. Non-commercial uses of the work are permitted without any further permission from Dove Medical Press Limited, provided the work is properly attributed. For permission for commercial use of this work, please see paragraphs 4.2 and 5 of our Terms (https://www.dovepress.com/terms.php). 
in another. ${ }^{16,17}$ The variable most consistently identified as an independent predictor of worse prognosis was an increased Acute Physiology and Chronic Health Evaluation (APACHE)-II score. ${ }^{3,4,6,11-14}$ Without a firm consensus, the predictive value of pre-ICU measurements, such as arterial blood gas, presence of specific comorbidities, and requirement for mechanical ventilation remains unclear. Furthermore, the majority of studies investigating patients admitted to ICU with COPD exacerbations had relatively small sample sizes. ${ }^{3-6,8,9,11,12,16-18}$

The aim of this study was to identify factors that are independently associated with hospital mortality for COPD patients with an acute exacerbation admitted to ICU.

\section{Methods}

\section{Ethical approval}

This study was reviewed and approved as audit activity by Research Governance of Peninsula Health (ref: QA/16/PH/2). As this was a retrospective study that required no patient contact and presentation of anonymized data, requirement for informed consent was waived.

\section{Study design and setting}

This was a retrospective cohort study of patients admitted to the ICU with exacerbation of COPD at Frankston Hospital. The 15-bed ICU located in Victoria (Australia) is a level III, university affiliated, teaching unit that admits $>1,100$ intensive care and high dependency patients per annum.

\section{Patients and data}

All adult patients admitted to the study ICU between 1 January 2005 and 31 June 2016 with a diagnosis of COPD were included in the study. Patients who had COPD as a known comorbidity but were admitted for management of another condition were excluded.

Data were collected retrospectively from the medical records of eligible patients. Demographic data included age, sex, and relevant comorbidities, including diabetes, hypertension, coronary artery disease, chronic renal failure, and arrhythmias. Other pre-admission variables included smoking status and use of home oxygen and systemic steroids.

Previous admissions to hospital or ICU for an exacerbation of COPD were noted. Physiological data included patients' partial pressures of oxygen and $\mathrm{PaCO}_{2}$ closest to ICU admission; their highest serum lactate 24 hours after admission; requirement of non-invasive ventilation (NIV) or invasive mechanical ventilation (IMV) and APACHE-II and III scores. Spirometry results from assessments conducted within 12 months prior to patients' ICU admission dates were analyzed. Variables extracted from these tests included vital capacity, $\mathrm{FEV}_{1}$, forced vital capacity, and diffusing capacity of the lung for carbon monoxide. Our intensive care management practices of exacerbation of COPD did not change significantly during the study period.

Patient outcomes included hospital and ICU length of stay (LOS) and mortality.

\section{Statistical methods}

Data were analyzed using SPSS $24^{19}$ and Mplus 8. ${ }^{20}$ To compare the differences between the survived and deceased groups of patients, chi-square tests were performed for the categorical variables and the continuous variables were assessed by the independent sample $t$-tests via SPSS program. The association between the independent variables and the binary outcome of hospital mortality was examined by logistic regression model using maximum likelihood estimation in Mplus.

\section{Results \\ Demographics and baseline characteristics}

Over the ten-and-a-half-year study period, there were 305 patients admitted to Frankston Hospital's ICU with a primary diagnosis of COPD. The mean age of patients was $67.41( \pm 10.49)$ years, and the majority were female (59.7\%). The most common comorbid condition was hypertension, seen in $52.67 \%$ of patients (Table 1), and over half $(61.3 \%)$ of patients were either current or exsmokers. One-fifth of patients $(20.5 \%)$ were being managed on home oxygen prior to hospital admission. A majority $(56.3 \%)$ of patients had been previously admitted to hospital for an exacerbation of their COPD and 16.7\% had previously required ICU admission. Other demographic data regarding our population are outlined in Table 1. On admission to ICU, patients had a mean APACHE-II and III scores of $17.83( \pm 6.75)$ and $60.59( \pm 22.71)$, respectively (Table 1). Patients' most recent lung function tests within 12 months prior to admission were also collected and our study population demonstrated an average $\mathrm{FEV}_{1}$ of $40.35 \%$ of the predicted value (Table 2). Other biochemical values and investigations can be seen in Table 2 .

\section{Hospital course and outcomes}

The average ICU and hospital LOS was 4.48 ( \pm 5.96$)$ and $11.6( \pm 13.05)$ days, respectively (Table 3 ). The ICU and hospital mortality were $11.5 \%$ and $18.7 \%$, respectively. Approximately one-third of patients required IMV $(n=104)$, and two-thirds required NIV $(n=218)$. 
Table I Differences in patients' characteristics between the surviving and deceased patients

\begin{tabular}{|c|c|c|c|c|}
\hline & $\begin{array}{l}\text { All patients } \\
(\mathrm{n}=305)\end{array}$ & $\begin{array}{l}\text { Surviving } \\
(\mathrm{n}=248)\end{array}$ & $\begin{array}{l}\text { Deceased } \\
(n=57)\end{array}$ & $P$-value \\
\hline Age (years) & $67.41( \pm 10.49)$ & $66.64( \pm 10.88)$ & $70.75( \pm 7.86)$ & $<0.0 \mathrm{I}^{\mathrm{a}}$ \\
\hline Male gender & $40.3 \%$ & $37.9 \%$ & $50.9 \%$ & $0.07^{\mathrm{b}}$ \\
\hline APACHE-II score $(n=304)$ & $17.83( \pm 6.75)$ & $16.94( \pm 6.36)$ & $21.65( \pm 7.12)$ & $<0.0 \mathbf{I}^{\mathrm{a}}$ \\
\hline APACHE-III score $(n=304)$ & $60.59( \pm 22.71)$ & $57.90( \pm 21.58)$ & $72.26( \pm 23.94)$ & $<0 . \mathbf{l}^{\mathrm{a}}$ \\
\hline SAPS-2 score $(n=292)$ & $37.69( \pm 14.86)$ & $35.74( \pm 14.11)$ & $45.77( \pm 15.3)$ & $<0.0 \mathbf{I}^{\mathrm{a}}$ \\
\hline Pneumonia at admission $(n=225)$ & $32 \%$ & $31.7 \%$ & $33.3 \%$ & $0.845^{\mathrm{b}}$ \\
\hline Systemic steroids $(\mathrm{n}=225)$ & $41.9 \%$ & $42.1 \%$ & $41.2 \%$ & $0.906^{\mathrm{b}}$ \\
\hline Home $\mathrm{O}_{2}(\mathrm{n}=224)$ & $20.5 \%$ & $16.8 \%$ & $38.5 \%$ & $<0.0 \mathbf{I}^{\mathrm{b}}$ \\
\hline \multicolumn{5}{|l|}{ Comorbidities } \\
\hline Diabetes $(n=274)$ & $22.6 \%$ & $23 \%$ & $20.40 \%$ & $0.85 I^{b}$ \\
\hline Hypertension $(n=28 I)$ & $52.7 \%$ & $52.6 \%$ & $52.90 \%$ & $1.000^{\mathrm{b}}$ \\
\hline Coronary artery disease $(n=28 I)$ & $32.7 \%$ & $32.6 \%$ & $33.30 \%$ & $1.000^{\mathrm{b}}$ \\
\hline Chronic renal failure $(n=298)$ & $5.37 \%$ & $5.3 \%$ & $5.60 \%$ & $1.000^{\mathrm{b}}$ \\
\hline Malignancy $(\mathrm{n}=298)$ & $12.08 \%$ & $11.9 \%$ & $13.00 \%$ & $1.000^{\mathrm{b}}$ \\
\hline Arrhythmia $(n=273)$ & $16.48 \%$ & $15.6 \%$ & $20.40 \%$ & $0.545^{b}$ \\
\hline Depression $(n=274)$ & $22.99 \%$ & $24.0 \%$ & $18.40 \%$ & $0.508^{b}$ \\
\hline \multicolumn{5}{|l|}{ Prior admissions for COPD } \\
\hline To hospital $(\mathrm{n}=215)$ & $56.3 \%$ & $54.7 \%$ & $63.9 \%$ & $0.313^{b}$ \\
\hline To ICU $(n=2 \mid 0)$ & $16.7 \%$ & $15.4 \%$ & $22.9 \%$ & $0.282^{b}$ \\
\hline
\end{tabular}

Notes: andependent sample $t$-tests; ${ }^{b}$ chi-square tests. Data shown as mean ( \pm standard deviation) or \%. Data in bold indicates statistical significant difference between the groups.

Abbreviations: APACHE-II score, Acute Physiology and Chronic Health Evaluation-II score; ICU, intensive care unit.

Table 2 Differences in physiological assessments between the surviving and deceased patients

\begin{tabular}{|c|c|c|c|c|}
\hline & All patients & Surviving & Deceased & $P$-value ${ }^{a}$ \\
\hline Diastolic BP, $\mathrm{mmHg}(\mathrm{n}=29 \mathrm{I})$ & $74.2( \pm 16.08)$ & $75.42( \pm 15.43)$ & $69.23( \pm 17.83)$ & 0.01 \\
\hline Mean BP, mmHg $(n=292)$ & $99.05( \pm 20.05)$ & $100.65( \pm 19.19)$ & $92.45( \pm 22.25)$ & $<0.01$ \\
\hline Systolic BP, mmHg $(n=291)$ & $147.20( \pm 31.55)$ & $149.63( \pm 29.72)$ & $|37.2|( \pm 38.8)$ & 0.02 \\
\hline Pulse rate, bpm & $107.47( \pm 24.64)$ & $107.61( \pm 23.53)$ & $106.89( \pm 28.99)$ & 0.86 \\
\hline Respiratory rate, brpm $(n=290)$ & $28.84( \pm 9.49)$ & $29.04( \pm 9.04)$ & $28.0( \pm 11.16)$ & 0.51 \\
\hline Temperature, ${ }^{\circ} \mathrm{C}(\mathrm{n}=290)$ & $36.99( \pm 3.84)$ & $36.74( \pm 0.96)$ & $38.02( \pm 8.44)$ & 0.26 \\
\hline \multicolumn{5}{|l|}{ Biochemistry } \\
\hline Highest serum lactate, $\mathrm{mmol} / \mathrm{L}(\mathrm{n}=205)$ & $2.59( \pm 7.43)$ & $2.74( \pm 8.14)$ & $1.89( \pm 1.15)$ & 0.54 \\
\hline $\mathrm{PaCO}_{2}, \mathrm{mmHg}(\mathrm{n}=28 \mathrm{I})$ & $63.06( \pm 21.40)$ & $61.78( \pm 20.62)$ & $68.86( \pm 23.99)$ & 0.03 \\
\hline $\mathrm{PaO}_{2}, \mathrm{mmHg}(\mathrm{n}=282)$ & II.II ( \pm 90.05$)$ & $105.64( \pm 84.34)$ & $135.33( \pm 109.58)$ & 0.71 \\
\hline $\mathrm{HCO}_{3}, \mathrm{mmol} / \mathrm{L}(\mathrm{n}=265)$ & $27.86( \pm 11.62)$ & $27.77( \pm 10.52)$ & $28.25( \pm 15.38)$ & 0.79 \\
\hline $\mathrm{pH}(\mathrm{n}=266)$ & $7.39( \pm 0.75)$ & $7.4( \pm 0.77)$ & $7.38( \pm 0.65)$ & 0.87 \\
\hline Albumin, $g / L(n=276)$ & $38.94( \pm 10.89)$ & $38.65( \pm 9.42)$ & $40.28( \pm 16.00)$ & 0.49 \\
\hline Bilirubin, $\mu \mathrm{mol} / \mathrm{L}(\mathrm{n}=267)$ & $7.5( \pm 4.53)$ & $7.36( \pm 4.1)$ & $8.52( \pm 5.87)$ & 0.20 \\
\hline Creatinine, $\mu \mathrm{mol} / \mathrm{L}(\mathrm{n}=275)$ & $95.68( \pm 57.20)$ & $91.69( \pm 47.82)$ & I I $3.66( \pm 86.22)$ & 0.08 \\
\hline Glucose, $\mathrm{mmol} / \mathrm{L}(\mathrm{n}=283)$ & $11.15( \pm 4.5)$ & 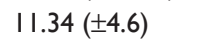 & $10.32( \pm 3.88)$ & 0.14 \\
\hline Hematocrit, \% $(n=280)$ & $0.45( \pm 0.8 \mathrm{I})$ & $0.43( \pm 0.63)$ & $0.5672( \pm I .3)$ & 0.49 \\
\hline Potassium, $\mathrm{mmol} / \mathrm{L}(\mathrm{n}=282)$ & $6.3( \pm \mid 2.61)$ & $5.89( \pm 10.85)$ & $8.55( \pm 18.46)$ & 0.32 \\
\hline Sodium, mmol/L ( $\mathrm{n}=283)$ & I55 ( \pm | | 3.40$)$ & $151.62( \pm 97.5)$ & $173.5( \pm 166.80)$ & 0.35 \\
\hline Urea, mmol/L $(\mathrm{n}=278)$ & $10.08( \pm 5.76)$ & $9.66( \pm 5.55)$ & $11.99( \pm 6.3)$ & $<\mathbf{0 . 0 1}$ \\
\hline WCC, $\times 10^{9} / \mathrm{L}(\mathrm{n}=276)$ & $12.98( \pm 6.16)$ & $13.69( \pm 5.83)$ & $15.39( \pm 7.4)$ & 0.01 \\
\hline \multicolumn{5}{|l|}{ Lung function test } \\
\hline $\mathrm{FEV}_{1}, \mathrm{~L}(\mathrm{n}=97)$ & $40.35( \pm 17.84)$ & $40.94( \pm 17.38)$ & $36.20( \pm 21.2 I)$ & 0.39 \\
\hline FVC, L & $70.82( \pm 20.62)$ & $71.11( \pm 21.32)$ & $68.56( \pm 12.74)$ & 0.70 \\
\hline VC, L & $39.05( \pm 37.86)$ & $36.64( \pm 38.20)$ & $67.98( \pm 16.46)$ & $<\mathbf{0 . 0 1}$ \\
\hline $\mathrm{DL} / \mathrm{VA}, \mathrm{mL} / \mathrm{min} / \mathrm{mmHg} / \mathrm{L}$ & $34.0( \pm 24.53)$ & $33.27( \pm 24.4 I)$ & $39.13( \pm 25.90)$ & 0.46 \\
\hline $\mathrm{DLCO}, \mathrm{mL} / \mathrm{min} / \mathrm{mmHg}$ & $31.91( \pm 13.87)$ & $32.17( \pm 13.8)$ & $30.35( \pm 14.7)$ & 0.67 \\
\hline $\mathrm{AaDO}_{2}, \mathrm{mmHg}$ & $80.6( \pm 150.18)$ & $68.18( \pm 131.05)$ & $131.60( \pm 205.94)$ & 0.08 \\
\hline $\mathrm{FiO}_{2}, \%$ & $0.44( \pm 0.23)$ & $0.422( \pm 0.22)$ & $0.5 I( \pm 0.27)$ & 0.04 \\
\hline
\end{tabular}

Notes: aAll comparisons were analyzed using independent sample $t$-tests. Data shown as mean ( \pm standard deviation). Data in bold indicates statistical significance. DL/VA, diffusing capacity divided by the alveolar volume; DLCO, diffusing capacity of carbon monoxide; $\mathrm{AaDO}_{2}$, alveolar-arterial oxygen difference.

Abbreviations: $\mathrm{BP}$, blood pressure; $\mathrm{FEV}_{1}$, forced expiratory volume in I second; $\mathrm{FVC}$, forced vital capacity; $\mathrm{PaO}_{2}$, partial pressure of oxygen; PaCO , partial pressure of carbon dioxide; WCC, white cell counts. 
Table 3 Differences in patient outcomes between the surviving and deceased patients

\begin{tabular}{|c|c|c|c|c|}
\hline & All patients & Surviving & Deceased & $P$-value \\
\hline ICU mortality & $11.5 \%$ & & & \\
\hline Hospital mortality & $18.7 \%$ & & & \\
\hline Hospital LOS, days & $11.63( \pm 13.05)$ & $12.2 \mid( \pm 13.65)$ & $9.09( \pm 9.66)$ & $0.10^{\mathrm{a}}$ \\
\hline ICU LOS, days & $4.48( \pm 5.96)$ & $4.12( \pm 5.46)$ & $6.04( \pm 7.60)$ & $0.07^{a}$ \\
\hline Proportion requiring NIV $(\mathrm{n}=282)$ & $77.3 \%$ & $79.7 \%$ & $66.0 \%$ & $0.03^{b}$ \\
\hline Proportion requiring IMV $(\mathrm{n}=269)$ & $38.7 \%$ & $32.1 \%$ & $66.7 \%$ & $<0.0 \mathbf{I}^{\mathrm{b}}$ \\
\hline Length of IMV, hours $(\mathrm{n}=65)$ & $127.18( \pm 179.49)$ & $103.72( \pm 152.38)$ & $173.06( \pm 220.03)$ & $0.19^{a}$ \\
\hline Length of NIV, hours $(n=158)$ & $107.97( \pm 70 \mid .58)$ & $106.36( \pm 755.80)$ & $117.42( \pm 181.99)$ & $0.88^{a}$ \\
\hline
\end{tabular}

Notes: andependent sample $t$-tests; ${ }^{b}$ chi-square tests. Data shown as mean ( \pm standard deviation) or \%. Data in bold indicates statistical significant difference between the groups. Abbreviations: ICU, intensive care unit; IMV, invasive mechanical ventilation; LOS, length of stay; NIV, non-invasive ventilation.

On univariable analysis, patients who died more often required IMV than those who survived $(66.7 \%$ vs $32.1 \%$, $P<0.001$ ) (Table 3). Furthermore, those who died during their admission were more likely to have higher APACHE-II, APACHE-III, and Simplified Acute Physiology Score-2 scores $(P<0.001)$, and were more likely to have been on home oxygen prior to admission (38.5\% vs $16.8 \%, P=0.002)$ (Table 1$)$. Those who died during their stay also had higher $\mathrm{PaCO}_{2}$ levels at admission when compared with those who survived (68.86 $\mathrm{mmHg}$ vs $61.78 \mathrm{mmHg}, P=0.03$ ) (Table 2).

The biochemical marker that was found to be significantly associated with overall mortality was a high blood urea concentration (11.99 vs $9.66 \mathrm{mmol} / \mathrm{L}, P<0.01)$. Patients who did not survive hospital admission also had significantly increased white cell counts (WCC) at ICU admission on average, compared with those who survived $\left(15.39 \times 10^{9} / \mathrm{L}\right.$ vs $13.69 \times 10^{9} / \mathrm{L}, P=0.01$ ) (Table 2 ).

\section{Multivariate analysis}

Table 4 shows that the significant factors associated with in-hospital mortality were increased age (odds ratio [OR $]=1.06,95 \% \mathrm{CI}: 1.03-1.10, P=0.004)$, longer ICU stay $(\mathrm{OR}=1.26,95 \% \mathrm{CI}: 1.02-1.57, P<0.001)$, higher APACHE-II score $(\mathrm{OR}=1.07,95 \% \mathrm{CI}: 1.01-1.12$, $P=0.02)$, and the requirement for IMV (OR $=4.09,95 \%$ CI: 1.79-9.32, $P=0.02$ ).

Table 4 Significant factors associated with in-hospital mortality examined using multiple logistic regression

\begin{tabular}{llll}
\hline & OR & $\mathbf{9 5 \%} \mathbf{~ C l}$ & P-value \\
\hline Age & I.06 & $1.03-1.10$ & $<\mathbf{0 . 0 I}$ \\
Hospital LOS & 0.79 & $0.63-1.00$ & $<\mathbf{0 . 0 I}$ \\
ICU LOS & 1.26 & $1.02-1.57$ & $<\mathbf{0 . 0 I}$ \\
APACHE-II score & 1.07 & $1.01-1.12$ & 0.02 \\
IMV requirement & 4.09 & $1.79-9.32$ & 0.02 \\
\hline
\end{tabular}

Note: Data in bold indicates statistical significant difference between the groups. Abbreviations: APACHE-II score, Acute Physiology and Chronic Health Evaluation-II score; ICU, intensive care unit; LOS, length of stay; IMV, invasive mechanical ventilation.

\section{Discussion}

This study investigated the outcomes of patients admitted to an Australian ICU following acute exacerbations of COPD over a 10-and-a-half-year period. In-hospital mortality during the study period was $18.7 \%$ and ICU mortality was $11.5 \%$. Age, requirement of mechanical ventilation, ICU and hospital LOS, and APACHE-II scores were found to be significant predictors of hospital mortality.

The hospital and ICU mortality in our study compares favorably to the other studies reporting hospital and ICU mortality for this patient group. The mortality rates recorded in this study are at the lower end of the ranges quoted from previous studies, with ICU mortality reported between $6 \%$ and 29\% $\%^{4-6,11,13,14,21}$ and hospital mortality ranging from $11 \%$ to $48 \% .^{3-14}$ This is likely to be related to improved standards of acute in-patient COPD care in recent years, as well as improved management of co-existing chronic illnesses.

The factors identified to be independently associated with hospital mortality in this study were consistent with those of other studies, including APACHE-II/III scores and age. $3,7,11,13,18,21$

Requirement for IMV was independently associated with mortality in our study. This finding is consistent with Ongel et al; ${ }^{13}$ however, six other studies failed to find any association between IMV and hospital mortality. 3,5,6,8,14,17 The exact mechanism of this association remains unclear; however, it is likely to be related to disease severity, with patients requiring IMV likely to be more unwell than those who do not require this intervention. Senneff et al found that, when controlling for severity of illness, IMV had no significant impact on mortality in the short or long term. ${ }^{14}$

ICU and hospital LOS were also found to be significant factors of mortality. Few studies have examined the relationship between LOS and in-hospital mortality. Hill et al reported that patients who survived their hospital admission had significantly longer periods of hospitalization than those 
who did not survive, ${ }^{11}$ while Ai Ping et al reported that longer duration of hospital stay was associated with increased risk of mortality. ${ }^{4}$ This is likely to be associated with end-of-life practices, which vary significantly between ICUs.

It has been well documented that higher $\mathrm{FEV}_{1}$ on spirometry is positively associated with longer-term survival of COPD patients. ${ }^{16,22-24}$ However, consistent with previous studies, ${ }^{4,6,17}$ spirometry values, including $\mathrm{FEV}_{1}$, were not significant independent factors of in-hospital and ICU mortality in the present study. Lower $\mathrm{FEV}_{1}$ suggests increased severity of COPD and therefore, should theoretically be associated with worse outcomes for patients admitted to ICU with an exacerbation of COPD. Unfortunately, only one-third of the sample had spirometry results available for analysis in the present study, and this may have influenced our findings. Likewise, previous studies investigating this association share similar limitations, with Raurich et al recording $\mathrm{FEV}_{1}$ and forced expiratory ratio for 70 patients out of $101 ;{ }^{17}$ Breen et al recording only 60 lung function tests out of $74 ; ;^{6}$ and $\mathrm{Ai}$ Ping et al only 57.4

Additionally, the time between baseline spirometry results and hospital admission for acute exacerbation varied within our sample, and this may have impacted on the validity of our findings. Some patients underwent spirometry many months before admission, while others received a baseline reading only weeks prior to hospital admission. This limitation is shared with previous studies investigating this association. ${ }^{4,6,17}$ A more uniform time interval between baseline spirometry and hospital admission may better elucidate the relationship between $\mathrm{FEV}_{1}$ and mortality in the ICU setting; however, achieving this is impractical. Indeed, further research into the role of spirometry predicting outcome of ICU admission for acute COPD exacerbations is required given its increasing use as a determinant of COPD severity under current practice. Given that many ICU admissions occur in the context of an acute exacerbation of COPD, it may also be important to consider patients' lung function during this acute illness in relation to their stable baseline.

Univariate analysis indicated significantly higher $\mathrm{PaCO}_{2}$, WCC, higher blood urea concentration, and lower blood pressure in patients who died compared with survivors (Table 2). These findings may be interpreted as representing a more severe exacerbation of COPD; however, these variables were not significantly associated with in-hospital mortality on multivariate analysis. Breen et al have previously demonstrated that higher $\mathrm{PaCO}_{2}$ level was an independent predictor of in-hospital mortality among ICU patients with COPD; however, no other studies have replicated this finding. ${ }^{6}$ Previous studies have suggested that severity of non-respiratory organ system dysfunction during hospital admission may have greater importance in predicting short-term ICU and hospital outcomes, ${ }^{14,17}$ while signs of respiratory dysfunction (including hypercapnia) may have greater prognostic significance in the longer term. ${ }^{14}$

\section{Strengths and limitations}

The present study included patient data from over 10 years. Our population base for this group of patients is the largest to be studied in a Western country in recent years and therefore, the results of this paper have significant clinical utility in the management of patients in similar ICU settings. Similarly, this study includes data from more recent patient admissions, and is, therefore, better reflective of current clinical practice in the ICU management of acute COPD exacerbations.

In addition, this study was able to use patient databases to investigate a range of important clinical and biochemical variables, and their association with patient outcomes.

Despite this, the present study has a number of limitations that must be acknowledged. Data were collected from a single site, limiting its generalizability. Furthermore, given the retrospective nature of this study, data collection was limited to existing medical records, and not all variables were able to be collected from every patient in the sample. For example, only one-third of patients had appropriate spirometry results available, with many of these results also occurring at heterogeneous time intervals before hospital admission. We also did not record information regarding patients' resuscitation status and treatment limitations at admission to ICU.

The long-term survival and quality of life for patients requiring admission to ICU for an exacerbation of COPD are beyond the scope of the present study. In addition, no information was collected regarding patients' functional status or frailty prior to hospital admission. Such information may be useful to inform decision making and resource allocation in the ICU.

\section{Conclusion}

Mortality from COPD remains high, and exacerbations of COPD are a significant cause of hospitalization and ICU admission. In the present study, patient age, APACHE-II score, ICU LOS, and IMV requirement were independent factors associated with in-hospital mortality for patients admitted to ICU for acute exacerbations of COPD. Further research is needed to elucidate the relationship between baseline spirometry values and patient outcomes in the long and 
short term. Additionally, long-term follow-up of outcomes and quality of life post-ICU discharge would be beneficial.

\section{Disclosure}

The authors report no conflicts of interest in this work.

\section{References}

1. Celli BR, Macnee W. ATS/ERS Task Force, Force AET. Standards for the diagnosis and treatment of patients with COPD: a summary of the ATS/ERS position paper. Eur Respir J. 2004;23(6):932-946.

2. Erbas B, Ullah S, Hyndman RJ, Scollo M, Abramson M. Forecasts of COPD mortality in Australia: 2006-2025. BMC Med Res Methodol. 2012;12:17.

3. Afessa B, Morales IJ, Scanlon PD, Peters SG. Prognostic factors, clinical course, and hospital outcome of patients with chronic obstructive pulmonary disease admitted to an intensive care unit for acute respiratory failure. Crit Care Med. 2002;30(7):1610-1615.

4. Ai-Ping C, Lee KH, Lim TK. In-hospital and 5-year mortality of patients treated in the ICU for acute exacerbation of COPD: a retrospective study. Chest. 2005;128(2):518-524.

5. Alaithan AM, Memon JI, Rehmani RS, Qureshi AA, Salam A. Chronic obstructive pulmonary disease: hospital and intensive care unit outcomes in the Kingdom of Saudi Arabia. Int J Chron Obstruct Pulmon Dis. 2012;7:819-823.

6. Breen D, Churches T, Hawker F, Torzillo PJ. Acute respiratory failure secondary to chronic obstructive pulmonary disease treated in the intensive care unit: a long term follow up study. Thorax. 2002;57(1):29-33.

7. Connors AF, Dawson NV, Thomas C, et al. Outcomes following acute exacerbation of severe chronic obstructive lung disease. The SUPPORT investigators (Study to Understand Prognoses and Preferences for Outcomes and Risks of Treatments). Am J Respir Crit Care Med. 1996;154(4 Pt 1):959-967.

8. Conti G, Antonelli M, Navalesi P, et al. Noninvasive vs. conventional mechanical ventilation in patients with chronic obstructive pulmonary disease after failure of medical treatment in the ward: a randomized trial. Intensive Care Med. 2002;28(12):1701-1707.

9. Conti V, Paone G, Mollica C, et al. Predictors of outcome for patients with severe respiratory failure requiring non invasive mechanical ventilation. Eur Rev Med Pharmacol Sci. 2015;19(20):3855-3860.

10. Fuso L, Incalzi RA, Pistelli R, et al. Predicting mortality of patients hospitalized for acutely exacerbated chronic obstructive pulmonary disease. Am J Med. 1995;98(3):272-277.

11. Hill AT, Hopkinson RB, Stableforth DE. Ventilation in a Birmingham intensive care unit 1993-1995: outcome for patients with chronic obstructive pulmonary disease. Respir Med. 1998;92(2):156-161.
12. Nevins ML, Epstein SK. Predictors of outcome for patients with COPD requiring invasive mechanical ventilation. Chest. 2001;119(6): $1840-1849$.

13. Ongel EA, Karakurt Z, Salturk C, et al. How do COPD comorbidities affect ICU outcomes? Int J Chron Obstruct Pulmon Dis. 2014;9: $1187-1196$.

14. Seneff MG, Wagner DP, Wagner RP, Zimmerman JE, Knaus WA. Hospital and 1-year survival of patients admitted to intensive care units with acute exacerbation of chronic obstructive pulmonary disease. JAMA. 1995;274(23):1852-1857.

15. Tang CY, Taylor NF, Mcdonald CF, Blackstock FC. Level of adherence to the GOLD strategy document for management of patients admitted to hospital with an acute exacerbation of COPD. Respirology. 2014;19(8):1191-1197.

16. Gudmundsson G, Ulrik CS, Gislason T, et al. Long-term survival in patients hospitalized for chronic obstructive pulmonary disease: a prospective observational study in the Nordic countries. Int J Chron Obstruct Pulmon Dis. 2012;7:571-576.

17. Raurich JM, Pérez J, Ibáñez J, Roig S, Batle S. In-hospital and 2-year survival of patients treated with mechanical ventilation for acute exacerbation of COPD. Arch Bronconeumol. 2004;40(7):295-300.

18. Khilnani GC, Banga A, Sharma SK. Predictors of mortality of patients with acute respiratory failure secondary to chronic obstructive pulmonary disease admitted to an intensive care unit: a one year study. $B M C$ Pulm Med. 2004;4:12.

19. Corp IBM. IBM SPSS Statistics for Windows, Version 24.0. Armonk, NY: IBM Corp; 2017.

20. Muthén LK, Muthén BO. Mplus user's guide. Sixth ed. Los Angeles, CA: Muthén \& Muthén; 2017. http://www.statmodel.com/ugexcerpts. shtml; 1998-2017.

21. Berkius J, Nolin T, Mårdh C, Karlström G, Walther SM. Swedish Intensive Care Registry. Characteristics and long-term outcome of acute exacerbations in chronic obstructive pulmonary disease: an analysis of cases in the Swedish Intensive Care Registry during 2002-2006. Acta Anaesthesiol Scand. 2008;52(6):759-765.

22. Anthonisen NR, Wright EC, Hodgkin JE. Prognosis in chronic obstructive pulmonary disease. Am Rev Respir Dis. 1986;133(1):14-20.

23. Incalzi RA, Capparella O, Gemma A, et al. The interaction between age and comorbidity contributes to predicting the mortality of geriatric patients in the acute-care hospital. J Intern Med. 1997;242(4): 291-298.

24. Rieves RD, Bass D, Carter RR, Griffith JE, Norman JR. Severe COPD and acute respiratory failure. Correlates for survival at the time of tracheal intubation. Chest. 1993;104(3):854-860.
International Journal of COPD

\section{Publish your work in this journal}

The International Journal of COPD is an international, peer-reviewed journal of therapeutics and pharmacology focusing on concise rapid reporting of clinical studies and reviews in COPD. Special focus is given to the pathophysiological processes underlying the disease, intervention programs, patient focused education, and self management protocols.

\section{Dovepress}

This journal is indexed on PubMed Central, MedLine and CAS. The manuscript management system is completely online and includes a very quick and fair peer-review system, which is all easy to use. Visit $\mathrm{http}: / / \mathrm{www}$.dovepress.com/testimonials.php to read real quotes from published authors. 